\title{
A UBP e sua inserção no ensino de Matemática: Uma proposta utilizando a obra Matemática Lúdica de Leon Battista Alberti $(1404-1472)$
}

The UBP and its insertion the teaching of mathematics: a proposal using the work Matemática Lúdica of Leon Battista Alberti (1404 - 1472)

\author{
Ana Carolina Costa Pereira ${ }^{1}$ \\ Marina Oliveira Tavares ${ }^{2}$
}

\section{Resumo}

A Unidade Básica de Problematização - UBP, é um flash de memória discursiva que descreve uma prática social num campo da atividade humana que, por algum motivo, é eleito como um objeto de problematização disciplinar. Ela possibilita valorizar elementos tais como contexto, historicidade, informalidade e simplicidade que são aspectos importantes na prática escolar da Matemática, mostrando a importância da história e cultura da comunidade escolhida para a aplicação da problematização na educação. A UBP se utiliza de uma metodologia ativa, onde a partir de atividades investigativas o aluno se torna participante ativo no processo de construção de seu aprendizado. Nesse intuito, através da UBP, mostraremos que o papel do professor é estimular e permitir a discussão entre os alunos, conduzindo-os se necessário, permitindo que os alunos examinem, reflitam e discutam sobre a historicidade e cultura matemática, realizando assim o exercício do pensar. Neste artigo, apresentamos uma proposta de UBP a partir de estudos feitos na obra Ex ludi rerum mathematicarum (Matemática Lúdica) de Leon Battista. Dessa forma ao analisar a obra observam-se diversas práticas socioculturais inseridas que serão parte do objeto de pesquisa.

Palavras-chave: Unidades Básicas de Problematização (UBP). Ensino de Matemática. Matemática Lúdica. História da Matemática.

\section{Introdução}

\footnotetext{
${ }^{1}$ Docente da Universidade Estadual do Ceará (UECE) e do Programa de Pós-graduação em Ensino de Ciências e Matemática (PGECM) do Instituto Federal de Educação, Ciência e Tecnologia do Ceará (IFCE) - E-mail: carolina.pereira@uece.br.

2 Discente da Universidade Estadual do Ceará (UECE) e bolsista de Iniciação científica do Conselho Nacional de Desenvolvimento Científico e Tecnológico (CNPq). E-mail: marina.oliveira@aluno.uece.br.
} 
Durante décadas a formação inicial de professores de Matemática se preocupou em preparar os futuros docentes para enfrentar os desafios propostos nas matrizes curriculares atuais. Partindo desse pressuposto, o educador deverá exercer as suas atividades de forma crítica e reflexiva, fazendo uso da Matemática como um instrumento de auxilio para os seus alunos, desenvolvendo assim uma competência de excelência e um aguçado senso ético e estético. É nesse sentido, que a Unidade Básica de Problematização (UBP) possibilita capacitar discentes de licenciatura em Matemática e docentes a aplicarem em suas práticas tal conhecimento.

Nessa vertente, o professor tem extrema importância no processo educativo, porém, esse deve fazer uso de meios auxiliares, pois, sendo incapaz de utilizar novos recursos, não terá espaço na atual educação. D'Ambrosio (1996, p. 79-80) enfatiza que,

O professor que insistir no seu papel de fonte e transmissor de conhecimento está fadado a ser dispensado pelos alunos, pela escola e pela sociedade em geral. O novo papel do professor será o de gerenciar, de facilitar o processo de aprendizagem e, naturalmente, de interagir com o aluno na produção e crítica de novos conhecimentos (...).

Sendo assim, para intensificar e melhorar as possibilidades de metodologias considera-se a utilização de UBP uma proposta que, se empregado de forma correta, pode tornar as aulas de Matemática dinâmicas.

A UBP é um flash discursivo memorialístico de uma prática social, descrito por Miguel e Mendes (2010, p. 386 - Tradução nossa) da seguinte forma:

Um flash discursivo memorialístico que descreve uma prática social situada em um determinado campo de atividade humana, essa teria sido de fato realizada para se responder a uma necessidade (ou desejo) que teria se manifestado por um ou mais dessa comunidade de prática, em algum momento do processo de desenvolvimento dessa atividade humana.

Essa prática pode ter diferentes significados dependendo do grupo social e situação a qual será aplicada, mobilizando diferentes fins, instrumentos, métodos e objetos culturais dessa comunidade. Miguel e Mendes (2010, p. 383 - Tradução 
nossa) caracterizam práticas sociais e citam exemplos em diferentes contextos de utilização:

No entanto, uma prática não é sempre uma atividade, uma vez que a prática pode ser realizada em diferentes atividades, tendo em diferentes significados em função das diferentes finalidades que orientam o seu desempenho em diferentes atividades. Poderíamos, por exemplo, realizar a prática de mãos que aplaudem em uma festa de aniversário, para saudar o celebrante aniversário, ou na porta de uma casa sem uma campainha para chamar para seus habitantes, ou dentro de uma sala de aula para chamar a atenção dos alunos, ou mesmo aplaudindo um artista num concerto, bem como em muitas outras situações. E em cada um deles, a prática de "bater palmas" tem um significado diferente.

A partir dessas práticas sociais encontradas ao longo da história serão elaboradas as Unidades Básicas de Problematizações (UBP), em que os alunos levantarão soluções criativas para resolver as problematizações propostas. Nesse procedimento o aluno estará desenvolvendo o exercício do pensar.

A proposta de criação de UBP tem como objetivo colaborar na formação de docentes de matemática, com uma metodologia que enfatiza a participação do aluno no seu processo de aprendizagem, de maneira a torná-lo um cidadão crítico e agente transformador da sua realidade. A sua utilização no ensino contribui para a construção de significados conceituais ${ }^{3}$ e metacognitivos ${ }^{4}$ presentes na solução das problematizações propostas na UBP.

Alguns pesquisadores (SOARES, 2011; LIMA FILHO, 2013; PEREIRA, 2014), já propõem UBP envolvendo o Ensino de Matemática, entretanto, a construção e a aplicação de UBP ainda estão em crescimento.

Neste artigo, apresentaremos uma proposta de UBP a partir de estudos feitos na obra Ex ludi rerum mathematicarum (Matemática Lúdica) de Leon Battista, escrita por volta de 1452. Outras práticas matemáticas históricas podem ser inseridas utilizando a obra estudada, principalmente, estudando conceitos geométricos, no entanto, tomaremos aqui apenas o conceito de volume exposto em um dos problemas citados pelo autor.

\footnotetext{
${ }^{3}$ Conceituais: formulação de uma ideia por palavras.

${ }^{4}$ Metacognitivos: uso de habilidades estruturantes para o processo de aprendizagem desta ideia.
} 


\section{A obra Ex ludi rerum mathematicarum (Matemática Lúdica) de Leon Battista Alberti}

Na obra Ex ludi rerum mathematicarum (Matemática Lúdica) traduzida por Souffrin, tivemos a oportunidade de encontrar um pouco sobre a vida e obra do autor dessa obra histórica que leva diversas práticas históricas socioculturais, e tais informações descrevemos aqui em nosso artigo para um melhor estudo sobre ele e em específico a obra Matemática Lúdica.

Leon Battista Alberti nasceu na cidade de Gênova, Itália, em 1404. As informações sobre sua formação são imprecisas, assim relata Pierre Souffrin ${ }^{5}$ em sua contribuição na introdução da obra Matemática Lúdica. Segundo Souffrin (2006, p. 8), "(...) acompanhou o pai a Veneza, onde a família tinha interesses (como os tinha em Bruges e em Londres), e recebeu, na Universidade de Pádua, uma formação retórica clássica em latim e provavelmente em grego".

Após a morte de seu pai em 1421, por excesso de trabalho e motivos de saúde, ele interrompeu seus estudos, mas neste período de pausa ele passou a se dedicar aos estudos de Matemática, Ciências Naturais e Física, voltando a frequentar a universidade de Bolonha formando-se em Direito canônico. Nessa época, começaram os seus primeiros escritos literários, como as comédias Philodoxeos fabula e Intercoenales.

Leon Battista viu-se com uma cultura extensa, mas com a diminuição nas economias dos Alberti, conflitos com a família depois da morte do pai o levaram a ingressar na carreira eclesiástica. Nesse período ele pôde fazer grandes viagens, e consequentemente ter contato com as realizações da Antiguidade. O papa Eugênio IV the impulsionou em sua carreira, primeiramente como secretário do chanceler Biagio Molin (1432), depois como breviador ${ }^{6}$ da Cúria Romana.

\footnotetext{
${ }^{5}$ Astrônomo francês que contribuiu significativamente na obra Matemática Lúdica.

${ }^{6}$ Nome dado ao funcionário da Cúria Romana que expedia os breves
} 
Em 1434, Leon Battista acompanhou Eugênio IV em seu exílio para Florença e permaneceu lá até 1443. Foi nesse período que Leon ligou-se intimamente a criadores representativos do renascimento como Donatello. Florença possuía grande destaque em relação às artes, fato que levou o autor a ser influenciado por esta cultura artística. Leon participou de debates literários, multiplicou suas obras literárias e poéticas, e compôs Della famiglia (sobre educação) e De pictura (sobre pintura), obra dedicada a Filippo Brunelleschi ${ }^{7}$.

O autor em estudo manifestou intensa atividade até o fim de seus dias, produzindo tratados teóricos sobre arte, arquitetura e ciência, quando ingressou em Roma no ano de 1443, sendo protagonista de importantes feitos, por exemplo, Descriptio urbis Romae e De statua, e também de obras arquitetônicas como as fachadas do palácio Rucellai e da igreja Santa Maria Novella. Alberti foi considerado uma personalidade notável de sua época, dedicou-se ao estudo das artes e das ciências e foi considerado por muitos autores como um humanista renascentista. Leon Battista faleceu em Roma no ano de 1472. Souffrin (2006, p. 10) retrata sobre o entusiasmo de Landino ao falar sobre Alberti e sua relação com a ciência e a arte.

Onde situar Alberti, em que categoria de eruditos colocá-lo? Entre os físicos, talvez? Seguramente estava destinado a sondar os segredos da natureza. Mas havia um único ramo da matemática que ignorasse? Foi geômetra, aritmético, astrônomo, músico e o mais extraordinário especialista em perspectiva em muitos séculos. Seu brilho em todas essas disciplinas pode ser visto claramente nos nove livros sobre arquitetura que divinamente escreveu, que abrangem todo tipo de ensinamentos que reluzem de uma eloquência suprema. Ele escreveu sobre pintura, e também uma obra sobre escultura intitulada De statua. Não se contentou em escrever sobre essas artes, ele próprio as praticou com as mãos.

Ao analisarmos o livro de Leon Battista Alberti, podemos verificar uma dedicatória do próprio autor ao príncipe Meliaduse ${ }^{8}$. Observamos que a obra foi

\footnotetext{
${ }^{7}$ Leon Battista e Brunelleschi eram próximos, pois possuíam uma admiração mútua.

${ }^{8} \mathrm{O}$ marquês era muito entusiasmado pela ciência, mas as suas funções não lhe permitiam fazer uso da forma que ele desejava. Quando tornou-se amigo de Alberti lhe fez o pedido pela obra. Mas apenas 15 anos depois a obra foi publicada.
} 
escrita como resposta para alguns questionamentos do príncipe à Alberti (2006, p. 27) demonstrando que tinha interesse pelo estudo de ciências:

De Leon Battista Alberti ao ilustríssimo príncipe Meliaduse, marquês d'Este, estas páginas de entretenimentos matemáticos. Devo admitir que respondo bastante tardiamente, com esta pequena obra, aos anseios que Vossa Senhoria exprimiu. Poderia invocar muitas desculpas e razões, mas prefiro confiar-me a vossa indulgência e bondade, e pedir que me perdoeis. Vossa paciência talvez tenha sido compensada pelo prazer que espero sintais ao conhecer as coisas bastante lúdicas que aqui encontrareis reunidas, ou até mesmo ao pô-las em prática e delas se servir. Empenhei-me em descrevê-las mui claramente; devo, porém salientar que se trata de matérias bem sutis, cuja exposição não dispensa o leitor de um esforço de atenção. Farias-me felicíssimo se ficásseis com ela. (...)

A obra Ex ludi rerum mathematicarum (Matemática Lúdica) é composta por 20 resoluções de problemas referentes à Arquitetura, construção civil ou militar, topografia ou navegação, utilizando procedimentos matemáticos divididos em duas partes. Na primeira temos resoluções de problemas que exploram a medição no espaço (comprimento, largura, altura e profundidade). Já na segunda vemos resoluções de problemas mais variados. Nesta parte o autor descreve diversos procedimentos de medições e abordam alguns aspectos referentes à agrimensura, ao nivelamento de solo e à elaboração de mapas.

A escolha desta obra como nosso objeto de pesquisa deve-se a existência do livro em língua portuguesa, poupando o tempo de tradução, e pelo fato de o autor trazer na obra procedimentos notáveis para a resolução de problemas práticos de todos os tipos, facilitando o entendimento destas resoluções ao utilizar uma geometria que se chamava de geometria practica, com procedimentos bastante óbvios para o leitor moderno, não transmitindo uma geometria erudita, mas sim, uma simples compreensão, sem demonstrações, fundamentada por exemplos numéricos. Observamos também a simplicidade na prática destas resoluções, onde desperta no leitor o interesse e curiosidade de praticar tais métodos mencionados no livro. 


\section{As atividades investigativas como uma proposta metodológica ativa para o ensino}

As metodologias ativas são práticas que estimulam 0 ensino e a aprendizagem baseada nas habilidades por meio do pensamento crítico-reflexivo, no qual o professor está inserido e se compromete com o aprendizado do aluno. Elas estão atreladas ao trabalho colaborativo, pois promove o desenvolvimento de habilidade de estudo em grupo e estimula o estudo individual no ritmo de cada estudante.

O professor pode estimular e permitir a discussão entre os alunos, dirigindo quando necessário e propondo os recursos didáticos úteis para cada situação. Segundo Pereira (2015, p. 61) "as metodologias ativas utilizam a problematização como estratégia de ensino e aprendizagem, com o objetivo de alcançar e motivar o discente, pois diante do problema, ele se detém, examina, reflete, relaciona a sua história e passa a ressignificar suas descobertas".

Dessa forma, a aprendizagem ativa está pautada na participação ativa do aluno, sua atividade autoestruturante, o que supõe a participação pessoal do aluno na aquisição de conhecimentos, de maneira que eles não sejam uma repetição ou cópia dos formulados pelo professor ou pelo livro-texto, mas uma reelaboração pessoal. A problematização tem um papel fundamental nessa proposta metodológica. Mendes (2010, p. 39) esclarece essa ideia discutindo que "O modelo didático apoiado na investigação histórica pressupõe a participação efetiva do aluno na construção de seu conhecimento em sala de aula como um aspecto preponderante nesse procedimento didático."

Nesse sentido, as atividades investigatórias trazem essas possibilidades de aprendizado a partir da investigação em História da Matemática trazendo melhorias no ensino a partir de um estudo histórico epistemológico dos conteúdos matemáticos, de forma a explicar os "porquês" existentes nos conteúdos matemáticos escolares. 
A utilização de elementos como a cultura e o cotidiano em que o aluno está inserido é importante nesse processo, pois facilitam o aprendizado a partir de princípios aprendidos. Portanto, é necessário que o professor use de criatividade, com uma linguagem simples e direta, para a criação de atividades que envolvam a investigação histórica, de modo a instigar o aluno às reflexões e discussões no decorrer do aprendizado.

Para a utilização dessas atividades em sala de aula, existe um procedimento metodológico, ou seja, uma orientação sobre a aplicação dessa atividade. Segundo Mendes (2010), inicialmente o professor seleciona o tema interessado ao seu trabalho e escolhe as bibliografias que irão auxiliá-lo. Em seguida, decide o nível de orientação para cada trabalho, conforme as finalidades e as necessidades da turma.

Feito isso, é importante a construção de um trabalho final escrito contendo as reflexões acerca do tema investigado, incluindo um resumo do material examinado e sobre o que foi aprendido durante todo o processo de pesquisa. Vale ressaltar neste processo, a utilização das referências solicitadas durante o trabalho, para dar maior credibilidade a quem o apreciar.

São inúmeras as sugestões de atividades investigatórias que podem ser inseridas em sala de aula. Tais como: atividades manipulativas tiradas diretamente ou adaptadas da História da Matemática, construção de projetos de investigação em temas específicos, investigação em problemas históricos, em textos adaptados de fontes primárias, textos tirados diretamente de fontes primárias e o uso de vídeos de textos históricos, tirados de fontes primárias ou secundárias.

As atividades investigativas trazem ao aluno a oportunidade de desenvolver uma autonomia em adquirir e construir seu próprio conhecimento, buscando na sua própria experiência a compreensão e explicação própria sobre o mundo. Dessa forma, temos a UBP como uma atividade investigatória, onde trás uma significação maior ao aprendizado dos conteúdos matemáticos que os 
exercícios tradicionais, pelo fato de estarem embasados a uma relação histórica e social, que são elementos importantes neste processo de aprendizado.

\section{Sobre a aplicação da UBP em sala de aula no ensino de matemática}

Como toda metodologia ativa que pode despertar a curiosidade, à medida que os alunos se inserem na teorização e trazem elementos novos na aprendizagem matemática, a UBP se desdobra em inúmeras fases, dependendo do grupo que o docente conduzirá as aulas, para que o objetivo previamente determinado seja alcançado.

No primeiro momento da aplicação, segundo Miguel e Mendes (2010), é feito um processo de recapitulação na vivência educativa com os professores em formação, tendo como objetivo investigar e mobilizar práticas escolares de cultura matemática. Posteriormente, os participantes se dividirão em grupos para mobilizarem práticas escolares de cultura matemática, tratando de conteúdos específicos, tais como: trigonometria, logaritmo, funções, dentre outros, para depois produzirem textos sobre as mobilizações das práticas levantadas.

Dessa forma, esclarecemos os significados de expressões como: mobilização e problematização, evidenciando o papel que elas desempenham na formação do professor. Para, em seguida, caracterizar as mobilizações das histórias relacionadas à formação dos docentes, ressaltando o coletivismo entre os participantes, ou seja, os alunos. Eles problematizam as práticas de uma forma interativa e indisciplinar ${ }^{9}$. Observamos que, à medida que a metodologia da UBP é aplicada, os participantes se envolvem e com isso fazem levantamentos que podem produzir outras problematizações, não havendo diferenças entre eles, pois respondem às perguntas de forma consciente, sendo que as quais, são abertas à

\footnotetext{
${ }^{9}$ Aqui a palavra não é sinônimo de indisciplina, insubordinação. Mas quer dizer que a UBP não vai lidar apenas com uma disciplina específica, por exemplo, a Matemática.
} 
discussão, por causa da política de igualdade, possibilitando a discussão ética acerca dos temas abordados.

Terminado esse processo é feito uma problematização coletiva. Logo em seguida, de forma individual eles irão realizar a atividade e se dividirão em grupos para as discussões e começam a colocar em textos o que refletiu de forma individual a mobilização de práticas escolares de cultura matemática. Depois irão expor o que escreveram em uma apresentação, explanando as memórias que haviam refletido antes, abrindo para novas discussões.

São dadas instruções na hora das categorizações, que são feitas nos debates em grupos. Para que eles relacionem nesse momento, objetos de cultura matemática, métodos de ensino, normas e métodos de controle de comportamento dos alunos. Assim como, as normas que ditam os trabalhos dos professores e práticas de avaliações de aprendizagem matemática.

Concluído a etapa individual, os alunos retornam aos grupos para continuarem a investigação sobre a cultura matemática aplicada nas escolas, direcionando especificamente as práticas matemáticas aplicadas nesse ambiente. Após as questões levantadas pelo grupo, essas por sua vez, são problematizadas de forma coletiva. Depois das problematizações coletivas são disponibilizadas as referências e um conjunto de UBP. Depois da leitura, são colocadas perguntas a fim de discutir sobre a UBP mostrada.

De acordo com Miguel e Mendes (2010), na aplicação de UBP percebe-se que quanto mais fontes históricas forem disponibilizadas, mais discussões serão suscitadas pelos alunos. Por exemplo, sobre a cultura matemática de certo tempo até $\mathrm{o}$ atual, normas que alunos e professores tinham na comunidade escolar, entre outros assuntos que podem ser gerados nas discussões. De forma que sempre estarão criando linhas discursivas diferentes.

\section{Uma proposta de UBP: iniciando um estudo}


A partir das práticas socioculturais matemáticas encontradas na obra Ex ludi rerum mathematicarum (Matemática Lúdica) geramos a UBP que segue, a qual foi foi confeccionada para a formação inicial do professor de Matemática, com o intuito de uma posterior aplicação.

\section{Medição da profundidade do açude Castanhão como um projeto de conscientização ambiental}

Introdução: Nesta UBP, feita a partir da problematização histórica sobre medições de uma grande profundidade de água, convidamos aos alunos ao ato do pensar com relação a determinação da profundidade de um açude.

Conteúdos: Densidade e volume.

Objetivos: Utilizar os conceitos sobre densidade e volume para calcular a profundidade de grandes extensões de água.

Público alvo: Alunos do ensino fundamental II, em particular do $9^{\circ}$ ano.

Metodologia: Estruturada pelas propostas de UBP.

Problematização histórica: Na segunda parte do livro Matemática Lúdica, é descrito uma maneira de medir uma grande profundidade de água. Ele apresenta como determinar "a profundidade de uma laguna da qual não consegue atingir o fundo nem com a sonda nem com uma grande extensão de cabos grandes profundidades" (ALBERTI, 2006, p. 41). Veja o processo descrito:

Tenha um recipiente que possa conter água, um vaso ou uma xícara, ou o que quiser, e faça no fundo um pequeno furo. Tenha também uma noz-degalha de carvalho, fixe nela um pequeno pedaço de ferro da forma do sinal que representa o 5 nos ábacos, e enfie na galha a metade da maior ponta desse pedacinho de ferro, enquanto a outra metade permanece no exterior. Tenha chumbos com um peso razoável, que farão a galha correr até o fundo, e proceda de modo que esses chumbos, o recipiente e a galha estejam dispostos (...). Fixe um dos chumbos na galha, dirija-se a um lugar onde a profundidade da água foi previamente medida com sonda e informe-se sobre esta medida. Encha ali com água seu recipiente com água pura, e pese as substâncias que estavam na água. Feito isso, deixe cair na água a galha com seu chumbo e ao mesmo tempo deixe a água escoar do recipiente. A galha será arrastada até o fundo, e ao chegar lá, a extremidade marcada como C tocará primeiro o fundo, e a extremidade marcada como B irá inclinar-se para o solo de modo que a ponta A fixada no fio do ferro se destaque dele, e a galha sendo liberada voltará a superfície. Feche então com o dedo o 
recipiente para que não escape mais água, e em seguida pese o restante dela e o que falta. (ALBERTI, 2006, p. 41 e 42)
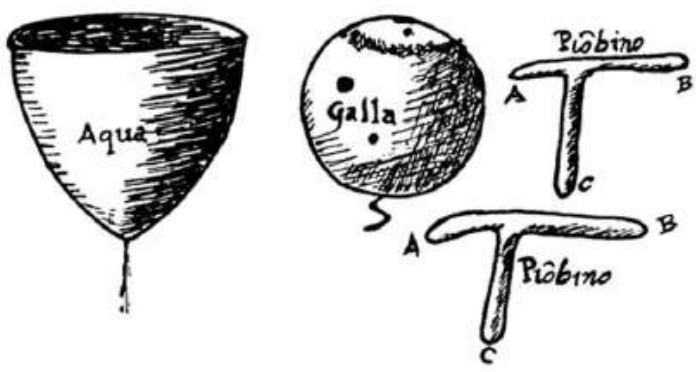

Explicando o método apresentado por Alberti (2006) de uma forma mais didática, temos o seguinte: fixe na galha um pedaço de ferro de forma que ele segure o chumbo que iremos colocar nele como peso. Antes de realizar o procedimento, tome conhecimento da medida da profundidade da água para que ao final se tenham comparações da medida com outros instrumentos e depois com o método de Alberti. Tome o recipiente com furo e inicie enchendo-o com água do local onde se pretende ter a medição. Certifique- se de que o furo nele esteja tapado. Em seguida, solte a galha com o chumbo enfiado nela, e, à medida que a galha desce na água com o peso do chumbo, destampe o furo e deixe a água escoar.

Quando a galha chegar até o fundo (ponto C) o chumbo irá se soltar dela ao tocar uma ponta (ponto A) no solo. Por isso, a galha voltará à superfície. Este então será o momento de tapar o furo do recipiente e verificar o quanto de água restou. Ao verificar o peso do conteúdo, teremos a medição que desejávamos e poderemos compará-la a medida que obtivemos anteriormente. Contanto, que não haja correnteza, este procedimento é bastante simples e satisfatório para medir grandes profundidades de água.

Problematização atual: $O$ açude Castanhão (figura 1) iniciou sua construção em 1995 no mandato do governador Beni Veras e foi concluído em 23 de dezembro de 2002 durante o governo de Tasso Jereissati.

Localizado no município de Jaguaribara-CE, possui uma capacidade de armazenamento de $6.700 .000 .000 \mathrm{~m}^{3}$ sendo considerado o maior açude para múltiplos usos da América Latina. Ele faz fronteira com quatro municípios cearenses: Nova 
Jaguaribara, Alto Santo, Jaguaretama e Jaguaribe. Suas águas são utilizadas para agricultura irrigada, psicultura, pesca (lazer, comércio e de subsistência), lazer náutico, assim como, através da construção do Canal da Integração, este açude disponibiliza água para abastecimento da população da Grande Fortaleza e para o Complexo Portuário do Pecém.

Figura 1 - Açude Castanhão

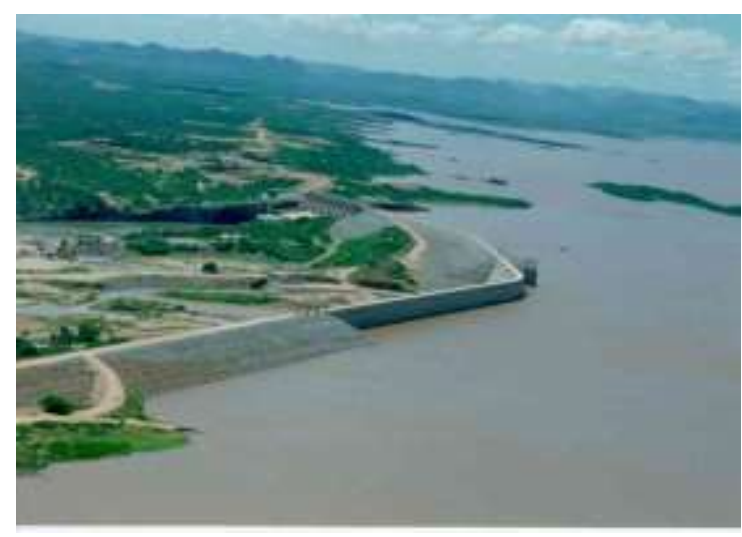

Fonte - Disponível em: http://www.dnocs.gov.br/barragens/castanhao/castanhao.html. Acessado em: 13nov2015.

Atualmente, o açude Castanhão conta apenas com $20 \%$ de sua capacidade total, devido quatro anos consecutivos de seca no Ceará. Mesmo sendo projetado para atingir a sua capacidade total, o maior açude da América latina não resistiu a falta de chuvas. Desde então, a água que estava acumulada no reservatório foi apenas liberada sem haver nenhuma reposição. O resultado é a redução rápida do volume de 
água. Outros fatores que contribuem para esta diminuição é a exposição do espelho d'água ao sol, causando evaporação.

Supondo que em sua cidade haverá uma conscientização ambiental e você fará parte desse projeto. Nele você irá falar sobre a problemática do açude Castanhão e como a população deve fazer a utilização adequada da água. Para isso, você precisará ter informações precisas sobre o volume de água e profundidade do açude. Com base no método sugerido por Alberti (2006) realize o procedimento para calcular a profundidade do açude Castanhão.

\section{Questionamentos}

1. A prática sociocultural encontrada na obra Matemática Lúdica sobre a medição da profundidade de grandes extensões de águas se mostrou adequada para cumprir tal propósito? Discuta a adequação dessa prática à realidade e problemas que tenham aparecido durante o processo com os recursos citados.

2. Atualmente dispomos de muitas tecnologias que nos auxiliam em diversas atividades. Descreva outras práticas que poderiam ser realizadas nesta problematização, e com base nelas resolva a questão sobre a problemática do açude Castanhão.

3. Descreva os instrumentos antigos e atuais utilizados para a medição da profundidade de grandes extensões de águas; explique o modo de utilizá-los e a base matemática de cada um deles.

4. O que significam os dados encontrados após o procedimento feito? Como podemos a partir deles saber a quantidade necessária de água para se utilizar no dia-a-dia sem haver desperdício?

5. Quem foi Leon Battista Alberti e por quais motivos teria construído o método apresentado?

6. Enuncie e resolva de outra forma um problema que envolva a medição da profundidade de uma grande extensão de água.

7. Esta UBP lida com conhecimentos de Geografia, Ciências e Matemática em sua problematização sobre a profundidade do açude e de que forma podemos usar a água de forma adequada, a partir dos dados que descobrimos durante os 
procedimentos. Você concorda que ela auxilia na interdisciplinaridade destas disciplinas? Descreva de que forma estão interligadas nesta proposta.

Consideramos que outros questionamentos podem ser elaborados utilizando práticas sociais advindas de atividades humanas, situadas próximas ao Castanhão, entretanto, somente após uma aplicação conseguiremos ampliar e melhorar o problema envolvido na UBP proposta.

\section{Considerações finais}

Em face dos desafios no ensino e aprendizagem de Matemática, novas estratégias metodológicas estão sendo estudadas e desenvolvidas como uma forma de contribuir para um melhor desempenho de estudantes, tanto na Educação Básica, quanto no ensino superior. É nesse intuito que a UBP pode ser considerada uma das estratégias metodológicas que vem ganhando espaço na comunidade acadêmica e que atua diretamente com as práticas sociais.

As reflexões aqui apresentadas sugerem a utilização da UBP como um meio de superação ao encapsulamento que a escola faz sobre o ensino de determinadas disciplinas, que por muitas vezes, limitam-se apenas ao repasse de informações descontextualizadas. Porém, tal metodologia em questão, visa relacionar a aprendizagem baseada nos estudos de Matemática à História nela subjacente, levando os alunos a articularem história, a situações cotidianas, que muitas vezes são consideradas irrelevantes tanto por parte dos alunos, quanto dos professores.

Nossa intenção com esse artigo foi apresentar a UBP de forma simples e de fácil compreensão, mostrando as etapas da sua construção a partir de qualquer material escolhido pelo docente transformando-o em uma proposta didática para a aula de Matemática.

Como exemplo, escolhemos a obra Ex ludi rerum mathematicarum (Matemática Lúdica) de Leon Battista Alberti de 1452, para construir algumas UBPs. Temos consciência de que, a UBP apresentada aqui, ainda precisa ser melhorada e lapidada para uma possível intervenção na sala de aula. Apontamos também a possibilidade de 
inserir vídeos e quadrinhos, assim como sua primeira aplicação em cursos de formação inicial de professores de Matemática e futuramente no ensino fundamental e médio.

Dessa forma, consideramos que a UBP tem um potencial que pode ser aplicado em qualquer nível de ensino, proporcionando uma importante contribuição no processo de aprendizagem dos alunos. Assim como, aos conteúdos matemáticos estudados em sala de aula, com as linhas discursivas que a UBP oferece, aguçando no aluno um senso crítico e reflexivo. Com isso, formar uma comunidade de alunos que refletem sobre o que aprendem de uma forma mais dinâmica e prazerosa.

\section{Referências}

ALBERTI, Leon Battista. Matemática Lúdica. Edição apresentada e comentada por Pierre Souffrin. Tradução de André Telles. - Rio de Janeiro: Jorge Zahar, 2006.

D'AMBROSIO, Ubiratan. Educação Matemática: Da teoria à prática. Coleção Perspectivas em Educação Matemática - Campinas, SP: Papirus, 1996.

LIMA FILHO, Renato Rodrigues Cunha. Um Estudo de Práticas Matemáticas Históricas e Sugestões de uso na Matemática Escolar. Dissertação (Mestrado em Ensino de Ciências Naturais e Matemática) - Universidade Federal do Rio Grande do Norte, 2013.

MENDES, Iran Abreu. A investigação histórica na formação de professores de matemática. Revista Cocar, v.4, n. 7 (2010).

MIGUEL, Antonio; MENDES, Iran Abreu. Mobilizing histories in mathematics teacher education: memories, social practices, and discursive games. In: ZDM Mathematics Education, n. 42, p. 381-392, 2010.

PEREIRA, Daniele Esteves. Correspondências Científicas como uma relação didática entre História e Ensino de Matemática: $O$ exemplo das Cartas de Euler a uma Princesa da Alemanha. Tese (Doutorado em Educação) Universidade Federal do Rio Grande do Norte, 2014.

SOARES, Evanildo Costa. Uma Investigação Histórica sobre os logaritmos com sugestões didáticas para a sala de aula. Dissertação (Mestrado em Ensino de Ciências Naturais e Matemática) - Universidade Federal do Rio Grande do Norte, 2011. 